En la retaguardia con aire de copla. La Junta Central Pro Socorro y

Reconstrucción de España en el sur de Santa Fe 1936-1939

Sebastián Merayo

Anuario No 32 / ISSN 1853-8835 / 2020

http://anuariodehistoria.unr.edu.ar/ojs/index.php/Anuario/index

\title{
En la retaguardia con aire de copla. La Junta Central Pro Socorro y Reconstrucción de España en el sur de Santa Fe 1936-1939
}

\author{
In the rear with a couplet air. The Central Board for \\ Relief and Reconstruction of Spain in southern Santa Fe \\ 1936-1939
}

SEBASTIÁN MERAYO

Facultad de Humanidades y Artes, Universidad Nacional de Rosario (Argentina)

profmerayo@gmail.com

RESUMEN

El presente artículo se propone un estudio preliminar de la Junta Central Pro Socorro y Reconstrucción de España en tanto organización dedicada a la solidaridad con el bando republicano durante la Guerra Civil Española (1936 - 1939) en espacios locales del sur santafesino. El abordaje analítico recupera el herramental metodológico propuesto por la historia regional o local bajo una mirada que intenta complejizar la categoría de antifascismo en tanto desarrollo de nuevas prácticas y discursos que le dan contenido a la conformación de una amplia red de entidades por fuera de los ámbitos tradicionales como partidos políticos o sindicatos. El objetivo es ubicar el foco en el novedoso dinamismo que el conjunto de actores sociales le imprimió a esta Junta dando lugar a un unificado activismo social crítico y heterogéneo en tensión con los sectores conservadores del gobierno provincial y de la sociedad civil.

Palabras clave: Antifascismo; Junta; sur santafesino.

ABSTRACT

This article proposes a preliminary study of the Central Board for the Relief and Reconstruction of Spain as an organization dedicated to solidarity with the republican side during the Spanish Civil War (1936 - 1939) in local areas of southern Santa Fe. The analytical approach recovers the methodological toolkit proposed by regional or local history from a perspective that attempts to complicate the category of antifascism as the development of new practices and discourses that give content to the formation of a wide network of entities outside the scope traditional as political parties or 
unions. The objective is to place the focus on the new dynamism that the set of social actors gave to this Board, giving rise to a unified, critical and heterogeneous social activism in tension with the conservative sectors of the provincial government and civil society.

Keywords: Antifascism; Board; south santafesino.

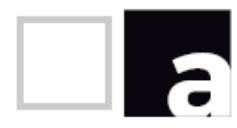

\title{
Introducción
}

\author{
"España, la de hoy, cantarte \\ quiero con aire de copla. \\ España de hoy, la que vive, \\ más que nunca luchadora..." \\ Álvaro Yunque (España, 1936)
}

España 1936, es un libro de poemas que el escritor argentino Arístides Gandolfi Herrero, bajo el seudónimo de Álvaro Yunque, le dedicaba en aquel momento a la España republicana. Por ese entonces Yunque escribía cuentos infantiles en el diario La Capital de Rosario. Con aire de copla se fue organizando la resistencia republicana antifascista en la retaguardia argentina.

Uno de los sucesos internacionales de mayor impacto en la politica, en la cultura y en la sociedad argentina de los años '30 ha sido la Guerra Civil Española (1936-1939) tanto por el enorme peso de la colonia hispánica en este país como por el devenir de una guerra en la cual su disputa ideológica se reflejaba en la sociedad y en la politica argentinas (Goldar, 1986; Quijada, 1991; Montenegro, 2002; Cattaruzza, 2006; Romero, 2011; Casas, 2016; Figallo, 2016; Campione, 2018).

Una extensa bibliografia historiográfica confirma que el drama español sacudió la escena mundial marcada por una amplia trascendencia que la ubicaba en antesala de la Segunda Guerra Mundial (Carr, 1974; Vilar, 2000; Hobsbawm, 2003; Traverso, 2009; Moradiellos, 2012).

\section{anuario.}


El presente artículo se propone un estudio preliminar de la Junta Central Pro Socorro y Reconstrucción de España ${ }^{1}$ en tanto organización dedicada a la solidaridad con el bando republicano durante la Guerra Civil Española en espacios locales del sur santafesino. En esta ocasión me propongo analizar y complejizar la problemática del antifascismo desde una perspectiva política de lo social dentro de lo que consideramos la historia regional o local. Estudiar la dinámica de una entidad habilita a pensar la espacialidad en tanto recurso metodológico para el análisis científico, que, al decir de Bandieri (2018), permite un "acercamiento comprensivo a una realidad social determinada en un espacio acotado, siempre en relación con una totalidad más abarcativa" (p. 8). Junto a ello la idea es la puesta en dialogo de lo regional con el concepto de redes, entendidas como trama de entidades étnicas, culturales, sindicales y politicas que lograron convocar de manera transversal un conjunto heterogéneo de actores sociales en la articulación solidaria con cada uno de los bandos en pugna de la España en guerra. Redes que, como en el caso de la Junta, aportan a una mayor complejidad de la categoría antifascismo y construyen el sentido social de la escala analítica.

El objetivo es poder discernir cómo una problemática internacional pudo contribuir a generar una novedosa cultura política a partir de la incorporación de nuevos discursos en los que se redefinian los temas y problemáticas en torno a los cuales habría de girar la vida pública en la Argentina de entreguerras.

Partimos del supuesto que este tipo ámbitos de militancia antifascista abarcan de manera transversal un conjunto de organizaciones (partidos, centros regionales, sindicatos) que pudieron establecer un discurso crítico frente al autoritarismo reinante de esos años a la vez que un activismo militante con capacidad de congregar en la práctica una diversidad de sujetos políticos (intelectuales, agrupaciones de mujeres, personas con escasa participación política, entre otras) y generar lenguajes que le dan una identidad propia al fenómeno del antifascismo.

De allí que en su retaguardia esta guerra haya significado, en sus múltiples niveles de impacto, la configuración de una renovada cultura política impregnada de nuevas prácticas, ideas y discursos en las que el drama español "desempeñó un papel articulador fundamental porque, a través de ella,

\footnotetext{
${ }^{1}$ De aquí en adelante nos referiremos a la misma de las siguientes formas: JPSRE, Junta Central Pro Socorro y Reconstrucción de España o simplemente la Junta.
} 
los actores fueron capaces de redefinir y replantearse sus propios problemas" (Montenegro, 2002: 2).

La importancia entonces de lo local está dada en la posibilidad de estudiar determinadas problemáticas, experiencias y conflictos en ese marco, porque va de suyo que siempre tendrá algo que lo particulariza resignificando lo global. Cuando pensamos en la trama local/regional del antifascismo estamos construyendo un proceso de identificación que le confiere sentido a un grupo social y le otorga estructura significativa para asumirse como unidad, conteniendo en sí diversos niveles o planos de identificación que pueden ser el generacional, el de género, el étnico, el regional, el de clase, etc. (Fernández, 2007: 37).

Este estudio se inscribe en la reciente línea historiográfica referida al impacto de la Guerra Civil Española en espacios locales de Argentina (Cucurullu y Sdrigiotti, 1999; Fernández y Armida, 2000; Ardanaz, 2013; Bocanegra, 2014; Semprini, 2014, Casas, 2016). Estos trabajos establecen un análisis en espacios micros a partir de distintos paradigmas que le otorgan una mayor complejidad al objeto en estudio. Como muestra de su inteligibilidad, notamos que aportan una ampliación del horizonte analítico en el que se establecen nuevas variables como por ejemplo el recorrido de los actores políticos, de sociabilidades en disputas, el vínculo con el derrotero del exilio republicano a escala local o la perspectiva de género como forma de problematizar el concepto mismo de antifascismo. Variables que, además de ampliar dicho horizonte, generan una metodología de análisis a partir de estudios de personalidades, instituciones locales o de la prensa como una forma de enriquecer dicho impacto.

De esta manera, sumados a los trabajos que han priorizado este impacto desde lo nacional, en todos los casos notamos que, más allá de matices específicos, partimos de una primera consideración: fue un acontecimiento internacional a partir del cual la sociedad en general tomo partido por uno $u$ otro bando.

Nuestra mirada abreva en la idea de que la diversidad de actores locales que adscribió al bando republicano en el sur santafesino no estuvo exenta de matices y debates en torno a los fenómenos europeos y también nacionales. Pero supo encontrar una serie de denominadores en común como la defensa de la democracia, de la cultura, de las libertades individuales, la oposición al franquismo en España y a los conservadores en Argentina, entre otros. A ello le sumamos el ejercicio práctico del nucleamiento organizativo a través de experiencias como la Junta. Este esquema encuentra su unidad en el apelativo antifascista y alli podrian incluirse tanto radicales como socialistas, demócratas, comunistas e incluso el anarquismo local que, más allá de las diferencias con el resto, tuvo una importante presencia en el sur de Santa Fe

\section{anuario.}


durante este período. Al pensar el antifascismo en tanto lógica de apelación discursiva, coincidimos con Bisso (2007) en que el recurso discursivo de lo anti, el antifascismo y en nuestro caso el antifranquismo republicano, fue conformando una identidad positiva que, en su imprecisión conceptual y en su composición heterogénea, será el elemento aglutinador y unificador.

El aporte del tema es demostrar que en la praxis, además de estos espacios políticos bien definidos, lo verdaderamente destacable fue el protagonismo anónimo de la sociedad civil. Si bien la Junta no fue la única organización de ayuda a la República, supo constituirse en una experiencia telúrica que le dio sostén y expresó esa dinámica por fuera de los cauces tradicionales de organización social. De allí se desprende su diseminación territorial, sus actividades y la destacable participación de las mujeres.

El estudio documental está centrado en fuentes dispares. Dos periódicos de tiradas locales como el diario La Capital y La Tribuna de Rosario. En el primero era muy común la publicación de las noticias bajo el titulo Sucesos Españoles. El segundo, de filiación demócrata progresista, tuvo una fuerte impronta pro republicana. Las noticias internacionales salian en la tapa y utilizaban la fotografia. Decenas de personas se agrupaban en su puerta a esperar los cables internacionales con las últimas noticias. A ellos le sumamos El Orden de Santa $\mathrm{Fe}$, de inspiración conservadora y La Vanguardia, el periódico del Partido Socialista Argentino. Para el análisis de la Junta, también hemos tomado algunos folletos de la Colección Calzadilla del Museo Histórico Julio A. Marc de la ciudad de Rosario.

En primer lugar, indagaremos los avatares del antifascismo en Rosario y el sur santafesino a través de las redes de ayuda con la República Española. En segundo lugar, tomaremos el análisis de la Junta a partir de su conformación, sus propósitos, sus debates y disidencias internas. Y, en tercer lugar nos vamos a centrar en tres cuestiones que consideramos complejizan las características del antifascismo local: el desarrollo de sus actos públicos, de las campañas y el rol de las mujeres.

\section{El objeto y la escena}

Traducido al castellano como "Historia del siglo XX", el famoso libro de Eric Hobsbawm (2003) tiene como título original The age of extremes, "la era de los extremos". No vamos a cuestionar aquí la validez de las grandes hipótesis del libro, sólo vamos a remarcar que, efectivamente, el siglo XX estuvo marcado por grandes conflictos y enfrentamientos, algunos de los cuales dividieron 
profundamente a la sociedad. Pero no en todos los casos lo hicieron de la misma manera $\mathrm{y}$, en verdad, muchas de esas "brechas" tomaron características particulares en virtud de las condiciones y luchas politicas y sociales de su contexto específico.

Desde 1936 y durante los siguientes 40 años, el 18 de julio sería celebrado en España como la fecha del Movimiento. Fue el día en que desde Canarias, el general Francisco Franco daba inicio a un golpe militar proclamando el Estado de guerra. (Carr, 1974; Vilar, 2000; Moradiellos, 2012). El golpe de estado a la República Española, encabezado por un grupo de generales, colocó la defensa de la República como el lugar privilegiado donde vastos sectores harían frente al fascismo en el centro del mundo. No es nuestro objetivo hacer un balance sobre la guerra en sí (existe una amplia literatura sobre ello), pero vemos pertinente remarcar que la misma se desarrolló en un contexto crítico, de desconcierto, en el que muchos valores y paradigmas se pusieron en juego (Hobsbawm, 2003; Bisso, 2005; Traverso, 2009).

En Argentina, la guerra supo aglutinar tanto a la derecha politica, organizada en torno de sectores conservadores autoritarios, nacionalistas, filofascistas y católicos integristas, en apoyo al bando nacional/franquista; como a un conjunto heterogéneo pro republicano, partidario del liberalismo democrático junto a distintos grupos de izquierda. Según estas interpretaciones, la amplia movilización social con el bando republicano, encontró un vértice de solidaridad y un punto de contacto que a la vez que se confrontaba con el fraude electoral y las políticas represivas del conservadurismo, también lo hacian con los espacios del nacionalismo que abiertamente se declaraban en apoyo del franquismo. (Romero, 2011; Casas, 2016; Figallo, 2016; Campione, 2018).

La crisis politica que no cesaba en Europa irrumpió en la escena nacional, de modo que

"el estallido de la guerra civil española vino a traducirla en un lenguaje inmediatamente inteligible a los argentinos [...] volvió a movilizar las energías de los predicadores del catolicísimo antimoderno [...] dio también ocasión para una casi póstumo despliegue de las pasiones que aun ardian bajo las cenizas entre los herederos de la variante argentina del liberalismo secularizador" (Halperin Donghi, 2013: 20)

Cuando achicamos el foco analítico, el tema se enriquece en función de sus características propias. En nuestro caso, el ambiente político estuvo dado por una intervención federal en 1935, que fue enviada por el ejecutivo nacional poniendo fin al gobierno del demócrata progresista de Luciano Molinas y que designó a Carlos Bruchmann como delegado del poder ejecutivo nacional en Santa Fe. En febrero de 1937 se realizaron los comicios para elegir gobernador; el candidato que contaba con las simpatías de la intervención y 
del propio Justo era Manuel María de Iriondo, de la disidente Unión

Cívica Radical de Santa Fe. El Partido Demócrata Progresista, desplazado del poder con la intervención, había llamado a la abstención, mientras que la facción de la Unión Cívica Radical que respondía al comité nacional levantaba la candidatura de Mosca (Montenegro. 2002). La intervención preparó un fraude escandaloso (Privitellio, 2002; Videla, 2006; Piazzesi, 2009; Mauro, 2013).

La gobernación de Iriondo contribuyó a enrarecer aún más el tenso clima político de la provincia. El contexto fue la sanción de las leyes de represión al comunismo y de Defensa Social en Santa Fe, y el debate por la Ley de Imprenta en la provincia en 1937 (Suarez, 2002). El imaginario conservador sobre el comunismo es el argumento que de manera legitimante y presuntuosa utilizaron para perseguir este tipo de actividades (Martin, 2019; López Cantera, 2019).

En mayo de 1937, en pleno activismo sobre la guerra, el gobierno provincial sancionó un decreto en el cual desautorizaba las reuniones públicas a favor de cualquiera de los bandos en pugna. Entre sus considerandos se establecía que la División de Investigaciones de la Jefatura de la policía de Rosario pasaba informes sobre los permisos otorgados a los actos públicos de la Junta, señalando que detrás de una aparente finalidad recaudatoria se habían notado militantes de ideología comunista (Fernández, 2017: 8)

Que esas reuniones se aprovechan para difundir su propaganda contra las autoridades constituidas y a los principios de la nacionalidad argentina [...]; que en la reunión [...] la mayor parte de la concurrencia llevaba puesto el característico gorro con aplicaciones que usan los llamados milicianos en España ostentan en el ojal de sus sacos una escarapela representando un puño cerrado, costumbre introducida por los propagandistas del comunismo y usada en la URSS (El Orden, mayo 1937)

Con esta cita del Diario El Orden, podemos ver la manera en que el recientemente asumido gobierno de Iriondo leía el accionar de las entidades y comités de solidaridad con la España republicana. A continuación haremos un breve repaso de la construcción local de las entidades antifascistas.

\section{El Antifascismo desde la aldea}

En la ciudad de Rosario la Intervención Federal marcó el fin de un periodo en el que el reformismo liberal había permitido establecer la Constitución provincial de 1921, lo que le otorgaba a la ciudad una autonomía política muy importante. Rosario, la ciudad portuaria, sufría también los avatares que la 
crisis económica había establecido en toda la estructura económica. La crisis social que acarreaba desocupación, hambre y miseria dejaban como legado una proliferación de zonas marginales sumado a una mayor pauperización de las clases subalternas. De pasar de ser un emblema del modelo agroexportador, en pocos años su geografía la ubicó en uno de los mayores corredores del denominado cordón industrial de la Argentina (Videla; 2006).

Para 1935 el fin de esta experiencia política democrática estuvo marcado por una serie de interventores nacionales que, en primer lugar, iban a derogar la Constitución de 1921 y, junto a ello, el inicio de una serie de gobiernos conservadores que devolvían la política provincial al esquema propuesto por el gobierno nacional (Mauro: 2013).

En todo este recorrido, el liberalismo politico del Partido Demócrata Progresista (PDP) devino en una suerte de paraguas político determinante para el activismo social y político en el campo de las izquierdas. El predominio del anarquismo local, la constitución de la Federación Anarco Comunista Argentina, el logro de bancas en el concejo municipal por parte de los comunistas, junto a un arraigado sindicalismo combativo, le daban un carácter cuanto menos dispar a lo que acontecía en el resto de la Argentina (Fernández y Armida, 2000; Suarez, 2002).

En julio de 1936 se realizaba en Rosario un funeral cívico en memoria de Enzo Bordabehere, Diputado Nacional por la provincia de Santa Fe, asesinado en el Congreso de la Nación un año antes, tras intentar defender al líder demócrata progresista Lisandro de La Torre, durante el debate sobre las exportaciones de carne a Gran Bretaña que establecía el pacto Roca-Runciman (La Tribuna, Rosario, 20/07/1936). El acto del PDP logró convocar a más de 50 mil personas en las inmediaciones del cementerio El Salvador. Eran personas que se congregaban para homenajear un símbolo de esta resistencia al gobierno de la "infamia" conservadora. En torno a la gran cantidad de actividades de homenaje a Bordabehere, el Centro de Unión Republicana de Rosario, enviaba una declaración en los siguientes términos:

El Centro Español de Unión Republicana de Rosario, se adhiere a ese homenaje póstumo, por lo que ello significa: el criminal cercenamiento de la vida de un paladin de las libertades democráticas ciudadanas: Enzo Bordabehere, ante cuya memoria el pueblo argentino rinde los honores de mártir de la democracia lo firman el vicepresidente J. Martin y el secretario J. M. Landevas. (La Tribuna, Rosario, 28/07/36)

Aunque esto no es lo único que completa el escenario. Se hizo además explicito un manifiesto pro conformación del frente popular en Argentina con una serie de denuncias por parte del Partido Comunista por las detenciones arbitrarias de varios de sus dirigentes, sobre todo sindicales y el terrible accionar de la Sección Especial de Represión al Comunismo. 
A propósito de los acontecimientos, el día 23 se publicó en los medios un discurso de Lisandro de La Torre en plaza Once. Entre otras cosas afirmaba:

"Los usurpadores conducen al despotismo y el despotismo conduce a la Guerra Civil. El pueblo pide verdad institucional y comicios libres y los que detentan el poder le contestan incubando una siniestra aventura" (La Tribuna, Rosario, 23/07/36).

Del armado en este frente popular encontramos, además del comunismo local, al PDP y al Partido Socialista, que se presentaban como fuerzas democráticas, populares y progresistas. Pero además, funcionaba desde hacía algún tiempo un comité de formación generando actividades, mítines y anuncios de convocatorias a cooperativas, sindicatos y vecinales que se quisieran sumar a tal iniciativa (La Tribuna, Rosario, 19/07/36).

Con esta imagen de fondo, el estallido de la Guerra Civil en España se tornó en un parteaguas tanto para el campo político como el mundo intelectual, artístico y social. Frente al avance del fascismo, se generó a nivel mundial un movimiento en Defensa de la Cultura occidental que a su vez se materializó en la solidaridad con la República, hecho que condujo a afirmar un posicionamiento (Hobsbawm, 2003; Bisso, 2005; Traverso, 2009). En este momento para la prensa los acontecimientos europeos eran los principales temas.

Más allá de nuestro inicial interés exploratorio en torno a la organización de la ayuda con el bando republicano, la intención es poder discernir cómo una problemática internacional pudo contribuir a generar una novedosa cultura política a partir de la incorporación de nuevos discursos en los que se redefinían los temas y problemáticas que impactaban en la vida pública argentina.

En ese sentido, observar a quienes optaron por una retaguardia republicana, se sugiere que esos actores "fueron capaces de construir un movimiento de masas en la Argentina" (Montenegro, 2002: 5). Y más allá de que quienes apoyaron al bando nacional recogieron apoyos políticos y recibieron también ayuda material "no tuvieron éxito -y probablemente no se lo propusieron- en hacer de sus postulados valores universales $y$, a partir de ellos, organizar $y$ movilizar en las calles a cientos de miles de militantes y simpatizantes" (Montenegro, 2002: 5).

Ante la ausencia de intervención oficial en el conflicto español, amplios sectores de la sociedad argentina tomaron partido por algunos de los bandos en pugna, pero el lado republicano a pesar de su heterogeneidad, supo 
aferrarse a la implementación de valores universalizantes, como la defensa de la cultura y de la democracia. Valores que expresaban un sentido de identificación discursiva, pero que se construyó en la escena pública y militante de la política:

"La evidencia en este aspecto es abrumadora, desde los niveles de participación en los actos públicos convocados por ambos sectores [...] los condicionamientos que la extensión del sentimiento pro republicano impuso a la política oficial del gobierno hacia el conflicto español” (Quijada, 1991: 17).

En Argentina, además de la centralidad que tuvo la embajada española como ámbito oficial, más de un millar de comités de solidaridad se pusieron en marcha a partir del comienzo mismo de la guerra. Según señalamos, fue un movimiento heterogéneo en el cual participaron diversos sectores sociales y políticos que le imprimieron matices y dinámicas propias.

Campañas de apoyo y de recolección de recursos, organización de comités de ayuda que se extendieron por casi todo el país, movilizaciones recurrentes en las ciudades, y una menos pública operación de envio de voluntarios fueron sostenidas por los partidarios de la República. Al comienzo de la guerra algunos rosarinos participaron como voluntarios en la conformación de las brigadas internacionales (Boragina, Dorado, González, Sommaro, 2008; Baumann, 2009).

Expresiones antifascistas existían ya desde la década del veinte, entre ellas agrupaciones como el Patronato Español de Ayuda a las Víctimas del Fascismo, el Socorro Rojo Internacional (SRI), el Centro Republicano Español, la Liga Española por los Derechos del Hombre, la Alianza Antifascista Italiana, el Comité de Mujeres contra la Guerra, entre otras. En 1934, luego de la represión al levantamiento de los mineros asturianos, se envió ayuda a los mineros desde el Patronato Español de Ayuda a las Víctimas Antifascistas, organismo ligado al Partido Comunista (PC) y al SRI.

A través de las noticas locales, podemos ver que con el inicio de la guerra numerosas organizaciones gremiales iniciaron actos de apoyo y recaudación de fondos. Lo importante a destacar es que, más allá de los debates que se generan, la lucha antifascista logra surcar un canal de participación social y un activismo político en un contexto de fuerte restricción a los posicionamientos más contestatarios "como herramienta discursiva capaz de movilizar a diversos sectores de la población y de congregar a distintos núcleos de dirigentes partidarios y cívicos bajo su manto” (Bisso, 2005: 41). En ese sentido, también fueron inevitables los roces entre radicales, socialistas, comunistas y anarquistas por el espacio local (Quijada 1991: 142).

\section{anuario.}


En este marco de movilización ascendente, las izquierdas y los sectores liberales encontraron un espacio para desplegar una acción militante que las circunstancias de la política le negaban. De allí que lo que denominamos antifascismo no se defina solo desde una lógica cultural o intelectual, sino que a partir de los procesos políticos que se fueron dando en esa década, se convirtieron en un marco de acción cuyo anclaje social muy importante, aunque no logró traducirse en términos electorales porque la lógica política de los gobiernos autoritarios era vetar todo tipo de articulación frentista, además de la imposibilidad de un acuerdo unitario entre los diversos actores de la política: "El desafio consistía en justificar cada acto realizado como un aporte más en esa lucha que -en el nivel mundial- se planteaba contra el totalitarismo y a favor de la libertad y la democracia” (Bisso, 2005). Fue un frente social que se constituyó por lo bajo, en torno a la solidaridad internacional, en el que participaron -hemos dicho- diversos actores como sindicatos, centros sociales, partidos políticos, asociaciones regionales, intelectuales, bibliotecas y, junto a ello, un amplio abanico social.

La construcción local del antifascismo fue adquiriendo caracteres particulares a lo largo de los años treinta. Desde los años veinte hay en Argentina una creciente apelación antifascista; sobre todo en los partidos politicos (Pasquali, 2016). Si bien en el Partido Socialista primaba la declamación democrática y liberal, en el comunismo local se destacaba la articulación de elementos pacifistas, antirrepresivos, antifascista y anticapitalistas.

La politica antifascista como plataforma en todos los frentes de masas, de forma más estratégica, se promovieron desde 1935 con la influencia del cambio de línea de la Internacional Comunista. Como un punto de inflexión del movimiento antifascista, desde 1935 se promovió la creación de frentes populares articulados sobre el eje antifascista, en su mayoría, estaban animados por el PCA (Pasquali, 2013).

Entre ellos encontramos: Comité sindical contra el fascismo y la Guerra, Comité popular antifascista, Alianza Juvenil Antifascista, Agrupación Mujeres contra la Guerra, Comité de Defensa Popular, Socorro Rojo Internacional, Comité juvenil de Echesortu contra la guerra y el fascismo, Comité Frente Popular Zona Sur, Comité pro Frente Popular Bella Vista, Comité pro presos y deportados (Cingolani y Frutos, 2003).

Proponemos pensar este periodo, que algunos han denominado década infame, no solamente como un periodo signado en el oscurantismo de gobiernos fraudulentos o una etapa de transición en el régimen político. De alli la importancia de estudiar las formas en que son traducidas las perplejidades de un mundo en vilo en espacios regionales a partir del análisis de prácticas, 
discursos y formas de organización institucional como las redes por fuera del Estado y de los partidos. Ubicando la centralidad del análisis en los nuevos modos de expresar y apelar las ideas politicas. En dicho sentido, la renovada producción historiográfica sobre el tema nos ayuda como modelo teórico a seguir.

En el desenvolvimiento de esta construcción social estalla la guerra en la península y en su retaguardia argentina la misma se traduce en la conformación de novedosos espacios de militancia y participación social, entre ellos la Junta Central pro Socorro y Reconstrucción de España.

\section{Redes de solidaridad antifascista}

"El mecanismo inicial de creación de los comités de ayuda era sencillo: un pequeño núcleo de dos o tres personas se trasladaba a un barrio urbano o a una pequeña localidad del interior. Alli...se realizaba una intensa labor de propaganda...la respuesta era inmediata y en poco tiempo quedaba constituido el comité, utilizando como sede cualquier local o casa o habitación cedido al efecto por una persona cercana al mismo. Individuos de diversa condición social y económica acudian a los comités, reclamando listas de suscriptores para hacerlas circular y devolverlas al poco tiempo llenas de firmas de donantes." (Quijada, 1991: 141).

El elemento central de las redes de solidaridad con la República lo constituyen los comités de ayuda. Los más humildes acudian con paquetes de ropa y viveres, campesinos entregaban granos o harina; otros, medicamentos, mantas, jabón, además de metálico.

En un primer momento la ayuda se organizó con un acentuado tono de apoliticidad. Las actividades vinculadas a algunos centros regionales y particularmente por la Cruz Roja (La Capital, Rosario, 18/08/36) sumado a otras instituciones como la Asociación Española de Socorros Mutuos, el Patronato Español, el Club Español y el Hospital Español hicieron un llamado a la solidaridad sin distinción de credos políticos. Una muestra de solidaridad y dolor por la tragedia que significaba la guerra. Sólo realizaron una extensión a personas que no pertenecian a la comunidad española, dejando en claro la postura de no discriminar ideológicamente el conflicto. Estas entidades tuvieron durante todo el desarrollo de la contienda la misma lectura. Pero lentamente la ayuda sería canalizada por instituciones que expresaban un tono de politicidad cada vez mayor. A la CGT y a sindicatos particulares hegemonizados por sectores de la izquierda, se sumaron los estudiantes y el abanico de los partidos políticos que no integraban la alianza de gobierno.

El desborde del cauce institucional fue provocado por la participación social. Desde el llamado al alistamiento de voluntarios hasta una cada vez mayor

\section{anuario.}


coordinación de la ayuda a escala nacional. El 1 de agosto de 1936 aparecía una de las más impactantes noticias locales, que reflejó de manera concreta el involucramiento de la sociedad civil rosarina con la Guerra Civil Española. Dice La Tribuna: "Comité de Alistamiento de Voluntarios"

\begin{abstract}
Se embarcarán rumbo a la madre patria. Patriotas. El Centro Español de Unión Republicana, ha constituido un comité Pro Alistamiento de Voluntarios. Esta mañana, un grupo de patriotas españoles, que se trasladará a la madre patria con el propósito de incorporarse a las fuerzas leales, visitó nuestra casa. El grupo de jóvenes anónimos está dispuesto a luchar por el mantenimiento de la República y espera órdenes de la embajada española en Buenos Aires para embarcar rumbo a la península (La Tribuna, Rosario, 01/08/36)
\end{abstract}

A medida que el conflicto avanzaba, junto a él, se acentuaba la toma de posición de las entidades a favor de uno u otro bando. En Rosario, el Centro de Unión Republicano, el Centro Asturiano, el Centre Catalá y la agrupación Andaluza fueron las primeras entidades españolas que expresaron defender a la República. A ellas se le sumó el abanico de organizaciones no españolas y es en ese sentido que planteamos el surgimiento de la JPSRE, en el centro de la escena de la ayuda antifascista, asumiendo la heterogeneidad ideológica y un irrenunciable compromiso por la España republicana (La Capital, Rosario; 02/07/1937). Lo mismo sucedió en el bando nacional a través de la Junta Nacionalista Española y la Falange Tradicionalista española local.

Si bien al interior del magma antifascista rápidamente afloran las diferencias, la Junta fue la que logró canalizar, a través de la creación de filiales y comités, la vasta participación social del movimiento. Dichos comités tenían un componente de pluralidad ideológica: "La politización de la ayuda era un proceso inevitable que no podía quedarse en los márgenes de una 'ayuda humanitaria'. La guerra era politica, antifascista y con una participación determinante de los partidos de izquierda y las centrales obreras" (Boragina et al, 2008).

Las organizaciones de alcance nacional fueron las principales protagonistas del desarrollo de los comités de solidaridad republicanos. Entre ellas se destacaron el Centro Republicano Español, la Comisión Coordinadora y Solidaridad Internacional, la Federación de Organismos de Ayuda a la República Española (FOARE).

La ciudad de Rosario estaba constituida por una gran colectividad española integrada por numerosos inmigrantes y sus descendientes. La prensa rosarina lo reflejaba a través de las noticias, las opiniones, el envio de corresponsales y sobre todo la actividad de los Centros Regionales Españoles destinadas al 
asistencialismo, la sociabilidad, sus festejos y celebraciones. El debate de lo que sucedía en España se trasladó al interior de los propios centros regionales (Cucurullo, y Sdrigiotti, 1999). La guerra se tradujo en una toma de posiciones que terminaron por 'politizar' a la sociedad (Boragina et al, 2008).

La actitud de los distintos centros fue bastante disímil. Algunos decididamente se enrolaron en el bando republicano, otros se unieron a la causa nacionalista y otros se embanderaron en una postura de supuesta apoliticidad. Existió una cierta correspondencia en los alineamientos de las colectividades a la disposición geográfica de los grupos en conflicto en la península. De este modo existian organizaciones como el Centro de Unión Republicana, el Centro Asturiano, el centre Catalá, la acción Nacionalista vasca y la Agrupación andaluza, que tomaron partido desde el estallido mismo de la guerra en defensa de la España republicana.

A nivel local la militancia en pos del apoyo material, intelectual y afectivo hacia la República española se hizo sentir especialmente desde el Centro Español de Unión Republicana, la Junta Pro Socorro y Reconstrucción de España y la Agrupación de Artistas, Intelectuales, Actores, Periodistas y Escritores (AIAPE) quienes a partir de diversas campañas durante el trienio 1936 - 1939, propiciaban distintos tipos de actividades. Estas tres entidades fueron muy importantes porque en ellas abrevaron una gran cantidad de actores provenientes de diversos espacios politicos. Tanto la AIAPE, como el Ateneo Luis Bello del centro republicano rosarino son dos entidades en la cual se reflejaba lo que Pasolini (2013) llama la construcción de una sensibilidad antifascista. Grupos de intelectuales, pensadores y artistas pasaron por estos ámbitos y con sus charlas e intervenciones, dieron identidad a la trama cultural del antifascismo en entreguerras. Un formato cultural en el que supieron convivir socialistas, comunistas, radicales, demócratas progresistas y anarquistas.

Por su parte, el socorro a víctimas y huérfanos de la Guerra Civil estuvo centralizado por la Cruz Roja y un grupo de mujeres que desde el Centro Republicano de Rosario realizaban campañas de ayuda.

A ello le sumamos que el movimiento obrero local, enrolado en la Confederación General del Trabajo $(\mathrm{CGT})^{2}$ y la Federación Obrera Local Rosarina (FOLR), en su conjunto realizaron un incuestionable apoyo a la causa republicana. La CGT hacía reiteradas convocatorias instando a colaborar en pro de la República española (La Tribuna, Rosario, 07/08/39). A1

\footnotetext{
2 Sindicato Gastronómico de Mozos y Anexos; la Federación de Obreros y Empleados Ferroviarios; la Federación de Trabajadores de la Empresa Municipal Mixta de Transporte de Rosario; el Sindicato de la Construcción; Sindicato de la Madera, entre otros.
} 
mismo tiempo los distintos partidos políticos ${ }^{3}$ se enmarcaron en un alineamiento de similares características.

En apoyo del bando nacionalista, se hicieron evidentes la fuerte presencia de la Iglesia Católica y las intervenciones de Monseñor Caggiano en las cuales enfatizaba el peligro del comunismo como una amenaza al orden social (Martín, 2019; López Cantera, 2020). Pero las organizaciones de mayor importancia en este sentido fueron la Junta Nacionalista Española de Rosario y el grupo Falangista de Rosario.

A medida que avanzamos en la exploración de datos dentro de este universo que constituyen las tramas de solidaridad, surgen tópicos muy importantes como el enorme protagonismo de las mujeres, la solidaridad obrera, la ayuda de las familias, el despliegue organizacional en los barrios de la ciudad, el desarrollo cultural e intelectual alrededor de esto y, en particular, un férreo activismo plasmado en las diversas entidades y actividades. Estos temas pueden visualizarse en el derrotero que haremos de la Junta.

\section{El caso de la Junta Central Pro Socorro y Reconstrucción de España}

La Junta Central Pro socorro y reconstrucción de España fue una organización netamente local que mantuvo vínculos con la FOARE. Esta Junta tenía, a diferencia del resto de las instituciones, un anclaje territorial en distintos lugares y distritos de la ciudad y un tipo de modalidad anclada en los comités de solidaridad. Si bien existieron juntas en varias ciudades del territorio nacional, la de Rosario fue la que más prosperó debido a su constancia en el trabajo y la organización. "Estas juntas fueron inicialmente el escenario de un muy ambicioso proyecto de ayuda económica a la República” (Quijada, 1991: 143).

En un primer momento, la actividad de ayuda al bando republicano se centralizó en las tareas del Centro de Unión Republicana de Rosario y su agrupación "Amigos de la República" (La Tribuna, Rosario, 30/08/36), pero rápidamente dicho activismo desbordó esta organización y, en ese sentido, la creación de juntas y filiales devinieron una necesidad. E1 25 de agosto de 1936 desde el Centro Republicano se forma el Comité de Amigos de España: "lo integraban 25 personas asistentes a la reunión, entre las que figuran varios comerciantes de la ciudad, un abogado, tres militantes de la FACA y varios del PC” (Quijada, 1991: 144).

\footnotetext{
3 El Partido demócrata progresista, la Unión Cívica Radical (comité nacional), el Partido
} Comunista, el Partido Socialista y la Federación anarco comunista argentina.

\section{anuario.}


La respuesta de la sociedad fue inmediata. Al respecto, el grupo de anarquistas de la $\mathrm{FACA}^{4}$ propuso ensanchar el radio de acción del organismo e incorporar otras agrupaciones y centros de ayuda. La tarea de este comité se fue ramificando en varios barrios de la ciudad y en diversas localidades de la provincia. Con el objeto de constituir filiales se convocaron asambleas en diferentes puntos de la ciudad (La Capital, Rosario, 11/11/1936). Tal es así que para el mes de enero de 1937 "estaban en funcionamiento 25 filiales en los diferentes barrios de la ciudad de Rosario y otras tantas en el interior de la provincia” (Quijada, 1991) Estos comités funcionaban bajo el nombre de Junta Pro Socorro y Reconstrucción de España, y la de Rosario era la Junta General.

La crónica del diario La Capital informaba sobre una gran concurrencia, desde representantes del comercio español en la ciudad hasta delegados de entidades gremiales, culturales y económicas. El secretario general, Eduardo Núñez de Ávila fundamentó el plan de la institución refiriéndose

"a la necesidad de movilizar la solidaridad nacional de todos los hombres españoles o no que tienen el sentido del deber para con la libertad, concretando a la vez en hechos prácticos el inmenso caudal afectivo que ha despertado la heroica lucha de nuestra madre Patria" (La Capital, Rosario, $13 / 11 / 36)$.

Bajo el nombre de Títulos al Portador, como una sintesis de la propuesta y el programa de socorro la JPSRE sintetizaba:

Hemos esbozado a largos trazos la sintesis del transcendental proyecto que ha de constituir el eje alrededor del cual se movilice y aglutine toda la opinión americana que simpatiza con la causa del pueblo español. Somos de opinión que deberán constituirse juntas de ese carácter en todo el país bajo la presidencia honoraria o efectiva del Embajador [...] Formarán en estas juntas todos los que estén dispuestos a apoyar al Gobierno Republicano Español, cualquiera sea su opinión política personal [...] El Comercio mayorista y minorista español...deberán ser la vanguardia de la patriótica cruzada [...] La Junta Central considera que todas las organizaciones culturales o de socorros mutuos españolas deberán integrar las juntas (La Tribuna, Rosario, 06/09/36)

Anuncian un gran acto en el Cine Real para el día 21 de septiembre de 1936, invitando especialmente partidos políticos nacionales, personas públicas, organizaciones comerciales, mutuales, gremiales y culturales. La mesa ejecutiva designó a Antonio Cordón y Eduardo F. Núñez de Ávila para invitar al embajador a presidir dicho acto y "a realizar importantes gestiones en el seno de la colectividad hispano-argentina de la metrópoli" (La Capital, Rosario, 07/09/36).

\footnotetext{
4 Federación Anarco Comunista Argentina
} 
El acto se realizó en el mes de octubre. Los oradores designados fueron el presidente de la Junta Antonio Cordón; el diputado nacional Manuel Ramírez, secretario general de la filial Buenos Aires; el representante de la FUA Narciso Marchinandiarena; el doctor Manuel Rodríguez del Centro Republicano español de Buenos Aires; María Luisa Petetin de la Junta Pro Socorro y Reconstrucción de España de Rosario; Casais Santaló, agregado comercial de la Embajada española y, además, Gregorio Berman, Enrique Corona Martínez, Carlos Sánchez Viamonte (PS), Leónidas Anastasi (UCR) y Alfredo Hercowitz (PDP). Se anunció asimismo la adhesión del Partido Comunista al acto (La Vanguardia, 11 /10/36).

Inmediatamente se fueron organizando juntas en varias seccionales de la ciudad. Las filiales reflejaban un gran activismo y participación social en torno a un solo objetivo: organizar la ayuda y la solidaridad de la España republicana. Aunque en el ambiente político de los años '30, el anclaje territorial de la Junta en sus múltiples secciones cobraria un carácter de politicidad que va más allá de un espacio de sociabilidad ciudadana y la sitúa como ámbito de participación social y política antifascista, es decir, como su inmensa tarea la coloca en el lugar de la disputa ideológica.

En la sección sexta, se anunciaba que

"la comisión ha invitado a todo el vecindario a concurrir al acto que promete asumir, por el entusiasmo reinante, lucidas proporciones y en el cual se expondrá públicamente el plan de socorro y reconstrucción de España...se procederá a elegir su CD." (La Capital, Rosario, 03/01/37)

A la par que la Junta iba desarrollando sus actividades y entidades barriales, lo propio iba sucediendo con la Junta Nacionalista Española de Rosario, que llevaba a cabo la ayuda al bando nacional. En la prensa local eran muchas las noticias de una u otra entidad, que se iban disputando la opinión y el espacio público convocando permanentemente a movilizarse para la ayuda. De allí el carácter de politicidad que fue adquiriendo la solidaridad disputada en entreguerras.

La conformación de su Segunda Sección fue anunciada a través de un comunicado:

"habiéndose avocado inmediatamente a la organización de los trabajos correspondientes, a fin de llevar a feliz término la ayuda de viveres, útiles y de toda clase de recursos, a favor del valiente pueblo español...hacemos un llamado cordial a todo los hombres y mujeres simpatizantes de la causa leal 
española, a fin de intensificar los trabajos correspondientes" (La Tribuna, Rosario, 04/02/1937).

Inmediatamente comenzó un imparable proceso de crecimiento en distintos barrios de la ciudad y localidades vecinas con actividades de diversa indole para recaudar todo tipo de ayuda. Esto lo conseguian a través de simples convocatorias de vecinos en domicilios particulares, aunque en varios casos utilizaban alguna otra institución como el Colegio Libre de Estudios Superiores, el campo deportivo del Centro Navarro, el Teatro Verdi de Cañada de Gómez, el Centro Republicano, la Casa de la Cultura (AIAPE).

Una de las primeras iniciativas fue organizar una suscripción de comercios locales a la que llamaron "Viveres para España" con el objetivo de recolectar alimentos y ropas adquiridos en comercios locales. De esta manera, además de contribuir a la obra humanitaria entendian que se debía fortalecer el comercio nacional. Mientras tanto, la junta directiva envió diversas solicitadas a comercios, frigoríficos y en especial a entidades españolas:

"Cámara Española de Comercio, Club Español, Institución Cultural Española, Patronato Español, Zazpirak Bat, Agrupación Andaluza y Centros Aragonés, Asturiano, Castilla, Catalán, Gallego, Navarro y Riojano invitándolas a apoyar la acción concretada en el plan de ayuda, ya conocido el valiente pueblo de la Península" (La Capital, Rosario, 19/09/36)

Durante el primer año se publican periódicamente sus actividades, que iban desde festivales, bailes, pic-nic, proyecciones de películas, espectáculos de orquestas, telegramas dirigidos al gobierno español, conformación de filiales nuevas, adquisición de nuevos locales, informes de los embarques, inscripción para donaciones, convocatoria de asambleas, entre otras actividades. De manera permanente se destacaba la masividad de la concurrencia y el compromiso, pero sobre todo, parecía primar un clima de festividad y optimismo en muchas de sus convocatorias. El crecimiento cobró tamañas dimensiones que desde la Junta Central, ubicada en calle Mitre 961, convocaron a la rápida realización de un Congreso.

Se efectuó anoche una reunión de la Junta Central...con asistencia de delegados de las distintas seccionales y barrios de la ciudad, y de los pueblos de la Provincia. Entre los puntos a considerar, se trató en modo especial, el relativo a la realización de un Congreso de organismos afines.... unificar tareas y acción (La Capital, Rosario, 16/12/36).

En un acto realizado en marzo de 1938 la tesorería de la Junta se encargó de especificar, además de los gastos, la entrada según las filiales. A través de esa lista conservada por la Colección Calzadilla podemos dimensionar el anclaje 
territorial en Rosario, o el mapa de la retaguardia republicana en el sur santafesino: Filial Villa del Parque y Parque Sud, barrio Alberdi, Parque Casas, Roque S. Peña, Barrio Triángulo, Coronel Bogado, Villa Diego, Cañada de Gómez, Ibarlucea, Barrio Carreras, Sección $7^{\mathrm{a}}$, San Francisquito, Central Santa Fe, Tiro Suizo y La Bajada, Sección $6^{\mathrm{a}}$,Barrio Arroyito, Bella Vista, Sección $8^{\mathrm{a}}$, Sección centro, Barrio Belgrano, Sección $9^{\mathrm{a}}$ y junto a las filiales la Comisión Central Femenina ${ }^{5}$.

Hacia finales del año 38 , las principales actividades de la Junta se centralizaron en calle Maipú 1027, compartiendo espacio físico con la AIAPE, en la Casa de la Cultura. Espacio en el cual también el Sindicato de la Construcción llevaba adelante muchas de sus asambleas. Todas coinciden en un anclaje muy cercano a la militancia comunista de la ciudad. Si bien el PC se había abocado a una actividad más específica a través de organizaciones como el Socorro Rojo Internacional y desde 1937 en la Liga Argentina por los Derechos del Hombre, poseía una notable influencia tanto en la AIAPE como en la JPSRE. A nivel nacional, la FOARE era la entidad de los comunistas para su ayuda a España.

Luego de la guerra, la Junta orientó su trabajo hacia la ayuda de refugiados y exiliados (Schwarzstein, 2000; Devoto, 2001). Desde la Casa de la cultura permanecieron centralizadas sus actividades bajo el nombre de Junta Central pro Socorro a los Refugiados Españoles, conservando la estructura de filiales en diferentes barrios de la ciudad y pueblos vecinos (La Capital, Rosario, 18/08/39). Poco tiempo después, esta entidad conformaba también la Comisión Central Femenina de Ayuda los Niños Españoles Refugiados. Con el devenir de la Segunda Guerra Mundial, la actividades de apoyo a las víctimas se desarrollaron a través de la Junta de la Victoria (Barrancos, 2019).

\section{Un plan, debates y disidencias}

Cuando se conformaba una filial, se pasaba a explicar la propuesta de un Plan de Socorro y Reconstrucción para España, lo que significaba un programa de préstamos en los siguientes términos:

- El gobierno republicano emitiría titulos al portador con el derecho a recibir en España, en cinco anualidades, 100 kilogramos de trigo o su equivalente en otras mercancías, cada título vale 15 pesos.

\footnotetext{
${ }^{5}$ Museo Histórico Julio A. Marc (Rosario). Colección Calzadilla
} 


\section{En la retaguardia con aire de copla. La Junta Central Pro Socorro y}

Reconstrucción de España en el sur de Santa Fe 1936-1939

- La primera emisión será de 200 mil toneladas de trigo o sea 30 millones de pesos enviando en canje: lana, algodón, cueros, grasas, carne, objetos de abrigo.

- La colocación es a cargo de las Juntas Pro Socoro, constituidas mediante procedimientos democráticos, bajo la presencia del embajador.

- Serían pagados en efectivo o mercancías. Campaña de propaganda para su colocación en el interior y las fábricas.

- La embajada rescataría los títulos al portador, devolviendo el $20 \%$ de su valor anualmente. Los titulos podrán ser enviados a sus familiares. (La Capital, 1936)

En simultáneo con la movilización popular a que daría lugar el empréstito, las juntas iniciarian una campaña para conseguir del gobierno argentino el redescuento de un préstamo al gobierno español. El argumento era que el empréstito iba a ser beneficioso también para Argentina, ya que luego de que la República ganase la guerra, su comercio se reorientaria hacia los países solidarios. Con el fin de presionar al embajador, la Junta le enviaba un cable al gobierno de Largo Caballero en Valencia:

"Primer Ministro Francisco Largo Caballero - Valencia: Junta Central Pro Socorro y Reconstrucción de España interpretando sentir popular asambleas extraordinarias rindiendo homenaje 14 de Abril, pedimos eleven embajador Jiménez de Asúa digno representante de España Republicana que con su valiente actuación ha hecho renacer entusiasmo y actividad pro ayuda Madre Patria" (La Tribuna, Rosario, abril 1937).

La firmaba su presidente Antonio Cordón.

Esta iniciativa fue impresa y entregada al embajador en Buenos Aires pero, ante la ausencia de garantías, fue rechazada. Terminó por generar mucho rechazo incluso al interior de la Junta, hasta llegar a la expulsión del secretario general. Se constituyeron al respecto dos comisiones, una de Control y Finanzas y la otra de Control en el Almacenaje de Mercaderías y Viveres (Quijada, 1991).

Las disidencias internas no faltaron $y$ en varias ocasiones hubo desplazamientos. "Los socios de la sección cuarta de la Junta, con motivo de los disensos internos habidos en la institución en su asamblea de elección de autoridades en mayo de 1937, acordaron por unanimidad desconocer la expresa entidad central y separarse" (Cucurullo y Sdrigiotti, 1999: 31) y constituir un nuevo organismo denominado Junta Pro Socorro de Guerra Alimentación para España Leal- (La Capital, Rosario, 12/06/37). De inmediato, el consulado hizo pública una declaración en la cual se desentendía de los conflictos internos aduciendo que "las cuestiones de orden interna de las mismas deben resolverse en el seno de la Junta Central" (La Capital, Rosario, Mayo 1937, s/f). 
En la ciudad de Rosario, la Comisión del Niño Español, perteneciente a la Junta Pro Socorro de Guerra -ubicada en Calle Corrientes 954- centralizaría las actividades de ayuda a la infancia española en peligro. Lo mismo hizo la sección local del Partido Aprista Argentino, se retiró de la Junta y prestó apoyo por su cuenta al gobierno de Valencia (Cucurullo y Sdrigiotti, 1999). En esta organización las disidencias fueron constantes, ya sea por un criterio de orientación política o por el tipo de ayuda que debía organizarse desde la entidad.

Aunque no solo en esta Junta había diferencias; si achicamos el foco veremos que el antifascismo no fue un campo sin fisuras. Hacia 1939 el embajador de la República Española en Argentina, Ángel Ossorio y Gallardo escribió para la revista del Centro de Unión Republicana de Rosario, Nueva España $(1939,4)$ las siguientes palabras que nos ayudan a esclarecer los matices ideológicos el resaltado es nuestro -:

Republicanos somos y seguiremos. Republicano será nuestro pensamiento. Demócratas, liberales, parlamentarios, constitucionales de 1931. En amistad franca con socialistas, comunistas, sindicalistas y anarquistas, aunque sin confundir ni un momento nuestra ideología con las suyas. Pensamos cosas absolutamente distintas y estamos accidentalmente unidos para combatir al enemigo común que es el fascismo. Nuestra posición es la misma de Inglaterra al buscar la unión con Rusia frente a los pueblos totalitarios (...) Cautela, prudencia, serenidad y buenos modos han de ser nuestras armas (...) quitarnos la leyenda de rojos (...) y mantener una respetuosa adhesión al legitimo Gobierno argentino (...).

Al interior del antifascismo podemos notar la pluralidad ideológica. Algo similar ocurría con la Junta: si bien la misma está ligada a la FOARE, en ella habia comunistas, anarquistas, demócratas y muchas personas independientes. Sus actos fueron una muestra de esa heterogénea composición social, política e ideológica.

\section{Con aire de copla. Actos y campañas republicanas en Rosario}

Los actos y las campañas fueron episodios en donde los valores más universales que comprendia la defensa republicana se ponian en juego. Tanto la solidaridad y el aporte de las personas a la causa republicana como la impronta de sus actos a través de las imágenes, la música, la simbología y la masiva concurrencia nos mostraban la incorporación de novedosos lenguajes que se impregnaron al drama político local. A partir de 1940, la Segunda 


\title{
En la retaguardia con aire de copla. La Junta Central Pro Socorro y
} Reconstrucción de España en el sur de Santa Fe 1936-1939

Guerra Mundial impondrá estos paradigmas en disputa a la agenda política oficial (Halperin Donghi, 2013).

\section{La solidaridad con la República Española en el sur de Santa Fe}

Las campañas comprendian al conjunto de las filiales y se desarrollaban según las posibilidades de solidaridad. En su mayoría se armaban a nivel nacional a través de la FOARE. Las de la Junta no eran las únicas, puesto que por su parte el Centro Español de Unión Republicana de Rosario también organizaba sus campañas a las que llamaba Racionamiento del Miliciano.

Desde el momento mismo en que se organizó la Junta, la solidaridad -como afirmamos anteriormente- fue una constante. Así, por ejemplo, con fecha del 18 de marzo de 1938, una carta enviada por el tesorero de la Junta, Isaac Calzadilla, en respuesta y agradecimiento a una persona que había donado la suma de dos pesos en moneda nacional y la compra por igual valor de tarjetas de ayuda a la comida del miliciano, decía: "oportunamente le enviaremos a usted el Balance de este gran acto de solidaridad y socorro al pueblo español"6. La carta dejaba entrever que la ayuda se organizó desde abajo según las posibilidades de cada persona.

A diferencia de los comunicados de la Junta Nacionalista Española en apoyo abierto al gobierno de Burgos, que

\begin{abstract}
"ha declarado categóricamente que es ella la única entidad, netamente definida en nuestra ciudad (ubicada en Calle córdoba 954), que reúne fondos con destino a las fuerzas del gobierno de Burgos que luchan para liberar a España del yugo de los extremistas sectarios detentadores del poder que asolan y enlutan" (La Capital, Rosario, 09/12/36),
\end{abstract}

La Junta se centraba en la ayuda a 'las víctimas de la guerra' sin hacer apreciaciones sobre el marco político de la misma, pero con un claro apoyo al bando republicano.

En base a su ligazón con la FOARE, las filiales de la Junta adhirieron a una de las campañas de ayuda más importantes, la Campaña del Cereal. En un comunicado de la Junta Vecinal de Ameghino se anunciaba que en dicha localidad se había realizado una colecta a favor de la Campaña del Cereal para remitir a la España republicana

"logrando reunir 102 bolsas de excelente trigo que ha sido consignado a la FOARE, representada en nuestra ciudad por la Junta Central Pro Socorro y Reconstrucción de España. El citado cereal ha sido descargado en el puerto

\footnotetext{
6 Museo Histórico Julio A. Marc (Rosario). Colección Calzadilla
}

\section{anuario.}


local en los silos de la Compañía Argentina de Elevadores, Recepciones y Embarques, S. A.” (Diario La Capital, Rosario, 4/07/38).

Similares noticias se replicaron en las localidades de Cañada de Gómez y Las Rosas. En octubre se anunció la salida de un barco con 850 bolsas de cereales de las siguientes localidades: Carreras, tres camiones con 500 bolsas; Villada, un camión con 51 bolsas; Corral de Bustos, un camión con 150 bolsas; Acebal, un camión con 21 bolsas; Chabas, un camión con 128 bolsas. Además, ambulancias, ropa, medicamentos y diversos tipos de productos recolectados por la JPSRE. En el mes de diciembre, la Junta comunicaba que la Campaña del Cereal había logrado reunir hasta 5017 bolsas para enviar (Diario La Capital, Rosario, 02/12/38). Dicha campaña culminó con un acto de masiva concurrencia en el Luna Park de Buenos Aires.

A esta altura la situación se tornó cuanto menos desesperante. Ello puede leerse en un cable publicado por el Comité Internacional de Coordinación de París, que decia: "Madrid telegrafia pidiendo reservas de leche en polvo para las criaturas agotada en la región central. Enviar inmediatamente ciento veinte toneladas. Treinta mil niños amenazados de morir de hambre..." reproducido en diversos diarios del mundo (La Capital, Rosario, 21/12/38).

\section{Manifestaciones antifascistas}

Complementando la proliferación de sus actividades en cada una de las filiales, la Junta también organizaba junto a otras entidades -AIAPE, Comité contra el Racismo, Centros regionales, Amigos de la República, Embajada española- actos públicos verdaderamente masivos. La impronta de estas movilizaciones fue una forma de visibilizar la ideologia en disputa.

En el marco de fechas representativas para los sucesos españoles, el 14 de Abril o el 12 de Octubre, se realizaron actos centrales en apoyo a la República Española en los cuales participaron las principales entidades de ayuda y solidaridad como algunos centros regionales, la Junta, el Centro Español de Unión Republicano de Rosario y demás entidades gremiales, culturales, estudiantiles y políticas bajo el amparo de la embajada como criterio de unidad y legitimidad. Por lo general, el espacio elegido era el Cine Real ubicado en la intersección de las calles Boulevard Oroño y Salta.

El 14 de abril de 1937, el Centro Republicano convocó a un acto en homenaje a la República española. La crónica es una seria descripción del ánimo popular en torno a los sucesos españoles:

Fue la de anoche una asamblea en la que el entusiasmo era tan grande como la multitud que se apiñó en todos los rincones de la espaciosa sala y

\section{anuario.}


en los alrededores de la misma...tanto el local como el proscenio y las calles adyacentes del teatro, ofrecian un espectáculo imponente. El escenario fue adornado con banderas argentinas y españolas y grandes retratos del general Miaja, de la Pasionaria, de Largo Caballero y de otros personajes (La Capital, Rosario, 15/04/37)

Aquí sí aparecía el claro repudio al fascismo y una gran participación de hombres y mujeres luciendo el gorro miliciano. Desde los palcos, las delegaciones de las entidades se hicieron reconocer por los respectivos carteles que las identificaban. El escenario estuvo ocupado por la delegación de Buenos Aires, los organizadores del acto y numerosas entidades obreras, estudiantiles y comités de ayuda. "Cuando el telón fue levantado, el público, con el puño en alto, prorrumpió en entusiastas vitores a la República Española, al gobierno de Valencia y el general Miaja, después de lo cual cantó el Himno Nacional, el Himno de Riego y la Marsellesa" (La Capital, Rosario, 15/04/37). Sin dudas que dicha descripción narraba el clima de época desde un simbolismo cargado de politicidad y compromiso que claramente los gobiernos conservadores no iban a tolerar por mucho tiempo.

Con motivo de este tipo de festejos y conmemoraciones, se organizaban distintos actos a los cuales la sociedad acudía masivamente. Eran actos que tenían una connotación menos formal, bailes, obras de teatros, conciertos y variedad artística muy importante. Todo bajo el clima del antifascismo.

La participación que provocaron los sucesos internacionales hicieron del espacio público un ámbito de disputa permanente acosado por un gobierno que, mediante decretos, intentaba frenar la movilización que causaba la conmoción española.

A través de la amplia convocatoria puede notarse que la JPSRE tuvo un anclaje territorial y social en las clases populares. En ese contexto el gobierno de Iriondo decreta suspender los actos en pro o en contra del drama español (El Orden, mayo 1937):

La reacción que se ha entronizado en Santa Fe teme a las reuniones populares aunque ellas sean de simpatía a una causa extranjera. Y tanto les teme, que cuando se organiza uno de estos actos, la policía previene a los organizadores que los oradores no deben tocar para nada la politica local (La Vanguardia, 08/05/37).

Un antecedente había sido la suspensión por parte del gobierno del principal acto del $1^{\circ}$ de mayo de 1937 (La Capital, 02/05/37. La Vanguardia, 03/05/37). En 1938 y 1939, la Junta tuvo sus propios oradores en los actos por el Día Internacional de los Trabajadores.

\section{anuario.}


En marzo de 1938, la Junta organizó una actividad recaudatoria bajo la consigna: Almuerzo del Miliciano ${ }^{7}$. Una lista de la colección Calzadilla muestra cuáles fueron los gastos y la entrada de dinero según lo aportado por las filiales adheridas. De esta forma podemos dimensionar cómo eran este tipo de jornadas. Además del dinero destinado para la comida y el transporte figuraban el alquiler del Centro Gallego, el permiso municipal, el sellado para el permiso policial, el pago a la orquesta, sus derechos de autores, la pegatina de carteles para invitar, algunos viajes de ómnibus, alquileres de mesas y sonido, los gastos a la delegación de Buenos Aires, el transporte de gaiteros, los cuidadores de la quinta del Centro Gallego, los artículos del tiro al blanco, entre otros, a los que podemos agregar los 326 litros de vino y 700 kilos de carne. Claramente se intentaba hacer un acto a través de los medios legales y con una masiva concurrencia.

Avanzado el desarrollo de la guerra, en septiembre de 1938, las actividades de la JPSRE se orientaron hacia un pedido de paz, posición que compartía con el conjunto de las entidades. A dos años de su constitución, esta Junta convocaría a un acto central al que denominó "Por la Paz", discurso que se aggiornaba a ese momento de la Guerra Civil Española pero que rápidamente volvería a desactivarse con la Segunda Guerra Mundial.

Como muestra de un acto unitario, el 27 de Noviembre de 1938 se realizó en la ciudad de Rosario un funeral cívico por los caídos en defensa de la República Española, en el cine Nacional, con la presencia del embajador de España en Argentina, Ángel Ossorio y Gallardo. Además del acto homenaje, en un contexto de extrema debilidad del frente republicano en la guerra, la movilización puso al descubierto todo el entramado de entidades adherentes a la República Española. Por la JPSRE tomó la palabra su nuevo presidente, Francisco Collado.

A finales de 1938, la FOARE cierra la Campaña del Cereal en un masivo en el Luna Park de Buenos Aires. Esta convocatoria atrajo la atención de toda la sociedad. El espacio elegido en Rosario para seguir el desarrollo del acontecimiento fue la Casa de la Cultura. En linea directa fueron escuchadas por altoparlantes las palabras del ministro español Indalecio Prieto. El acto estuvo organizado por la Junta, mostrando su postura de compromiso y activismo militante desafiando el autoritarismo estatal. La movilización que una vez más desbordó el espacio físico ocupando las calles en las

\footnotetext{
7 Museo Histórico Julio A. Marc (Rosario). Colección Calzadilla
} 


\section{En la retaguardia con aire de copla. La Junta Central Pro Socorro y}

Reconstrucción de España en el sur de Santa Fe 1936-1939

inmediaciones de la Casa, desafiaba la voluntad prescriptiva del gobierno provincial.

A medida que el final de la guerra se acercaba, las noticias sobre los hechos españoles y la acción humanitaria fueron una constante en los diarios locales. Notas a la Liga de las Naciones, a Inglaterra, a Francia, actividades intelectuales, pic-nic en quintas a las afueras de la ciudad, la campaña por los niños, refugiados, la campaña de invierno, y la permanente actividad de la JONS y de la Falange Tradicionalista Legionarios Franquistas, entre otras, eran las publicaciones más asiduas. A ello se le sumaron las numerosas asambleas y nuevas comisiones en las filiales.

Más allá de las numerosas charlas de la Junta Nacionalista 'celebrando' la paz, el fin de la guerra culminó con un acto antifascista de trascendencia internacional. La cita fue el Cine Real: "Pro Unión de las Democracias de América" organizado por AIAPE, la Liga por los Derechos del Hombre, el Comité contra el racismo y el Antisemitismo de la Argentina, la JPSRE y otras entidades (La Capital, Rosario. 02/04/39). En este acto público, en el que el orador central fue Pablo Neruda, por entonces cónsul del gobierno de Chile para la inmigración española en París, el objetivo era la defensa de las democracias frente al avance del fascismo en el mundo y solicitar ayuda para financiar el rescate de refugiados españoles en Francia a través del buque Winnipeg. El hecho dejó ver una masiva concurrencia de la sociedad rosarina en apoyo a la España republicana. Aunque algunos grupos menores celebraban la caída de la República y el ascenso del franquismo en aquel país.

Una vez finalizada la guerra y a raíz de una consulta de la Junta Vecinal del Cereal de Caseros a la Jefatura de Policía para realizar un acto público por las víctimas, quedó claro el rechazo por parte del Ministerio de Gobierno. El gobierno provincial decretó suspender todo acto relacionado con la situación española:

"Por la resolución se hace saber a los organizadores del acto que están prohibidas todas las reuniones públicas que tengan directa o indirectamente fines propagandisticos...que puedan exacerbar los ánimos de los españoles residentes...los organizadores deberán tener en cuenta la politica de prescindencia que supone la actitud adoptada por el gobierno" (La Capital, Rosario, 06/04/39)

A medida que la situación internacional recrudecía los niveles de violencia, se profundizaban las tareas destinadas a refugiados y exiliados de la guerra (Schwarzstein, 2000; Devoto, 2001). Como vimos, en 1939 la Junta adopta el nombre de Junta Pro Socorro a los Refugiados Españoles con su respectiva Comisión Femenina (La Capital, Rosario, 18/08/39). Hasta el final de la contienda mundial las tareas de las mujeres siguieron abocadas a la ayuda de 
las víctimas. En Rosario, la Junta de la Victoria fue la organización que logró nuclear la participación femenina (Barrancos, 2019).

\section{E1 Protagonismo de las mujeres}

Pensamos que en este escenario la participación política de las mujeres puede ubicarse en lo que Dora Barrancos (2019) denomina un interregno que duró hasta mediados de la década de 1940. Y, si bien representó una cierta declinación de las demandas femeninas, lo fue en función de una dominante preocupación por la

"atmósfera autoritaria y sus repercusiones locales. El mayor empeño militante estuvo destinado a socorrer a las victimas de la guerra civil española, a desplegar medidas solidarias con los refugiados y a proveer auxilio a quienes eran perseguidos por el nazifascismo" (Barrancos, 20191: 194).

La autora señala además que esto se traducía en una inquietud compartida entre las socialistas, radicales, católicas liberales y también las anarquistas en un mundo cada vez más asediado por la pérdida de libertades.

La participación de las mujeres en el heterogéneo campo del antifascismo no era nueva con la Guerra Civil Española, sino que la misma formaba parte de un contexto autoritario en el que las demandas más acuciantes estuvieron determinadas por la urgencia de la guerra. De esta forma veremos cómo la organización de mujeres en este tema se homologaba a una supuesta representación pacifica de la violencia, aspecto que no encaja cuando encontramos que muchas de ellas se enrolaron en el combate europeo (Edelman, 1996; 2013; Etchebéhère, 2015).

Desde la década de 1930 aparecieron agrupaciones como Agrupación Mujeres contra la Guerra, Federación Femenina Argentina Pro Paz Mundial, Comité Argentino de Mujeres Pro Huérfanos Españoles y Unión Argentina de Mujeres. Durante los años '40 se fundó la Unión de Mujeres Argentinas. En el caso de Rosario, tuvo un papel muy destacado la Escuela Profesional Rosalía de Castro, dependiente del Centro Español de Unión Republicana. Una escuela que tendría entre sus objetivos instruir a niños y niñas de la población pro republicana local y también destinada a ayudar a los refugiados en los campos de concentración en Francia luego de la guerra civil. Más tarde, ya en el contexto de la conflagración mundial, el espacio político de participación antifascista y femenino será la Junta de la Victoria (Pasquali, 2013; Hernández, 2015; Barrancos, 2019).

\section{anuario.}


Varios trabajos han puesto la mirada en el cruce antifascismo y mujeres planteándolo desde un análisis de las coyunturas y situaciones históricas (McGee Deutsch, 2012, 2013; Ardanaz, 2013; Pasquali, 2016). Entendiendo que más que un simple aspecto teórico, pensar el género implica una cuestión metodológica que nos lleva a examinar a las mujeres y a los varones en sus vínculos sociales, constituyendo la mirada sobre la construcción de la diferencia sexual (Scott, 1983).

Dicha mirada desde lo relacional supone indagar normas, instituciones, subjetividades y representaciones para comprender el clima y las estructuras sociales y culturales. En nuestro caso, el rol que adquirió la participación de las mujeres en la construcción del antifascismo debería entenderse dentro de la dinámica misma de dicho contexto en el que, sumada al carácter asambleario y organizacional de la Junta, aparecía tempranamente una voluntad pacifista, antibelica o de ayuda a la niñez en contexto de vulneración.

En una noticia en la que se informaba sobre la conformación de la comisión de veinte miembros de la sección séptima de la junta se establecía además que

"ha quedado constituida la filial femenina de la sección séptima, integrada por numerosas damas, quienes se abocaron de inmediato a la tarea de recolectar viveres y ropas entre el comercio y el vecindario. Al mismo tiempo será abierto un taller de labores para lo cual se cuenta con cinco máquinas de coser" (La Capital, Rosario, 15/10/36).

Aquí aparece el rol protagónico de las mujeres vinculado a quehaceres estereotipados y a la -ya citada- voluntad pacifista de su accionar.

La junta creó filiales pero también la Comisión Femenina encargada de la Campaña Pro Huérfano y Alimentación del Niño Español en alianza con mujeres de otras organizaciones. Así, La Tribuna informaba que

"La Sección Femenina de la Junta Central Pro Socorro y Reconstrucción de España ha invitado a todas las mujeres que desean colaborar en la campaña Pro Alimentación del Niño Español. Esta comisión se dirige a las mujeres argentinas que no pueden permanecer indiferentes ante tantas vidas destrozadas y tantos niños que sienten hambre" (La Tribuna, Rosario, 19/04/1937).

Por otra parte, es destacable señalar que durante el clima de retroceso que se vivía en el bando republicano y el aumento de las víctimas, desde mediados de 1938 tomó mayor fuerza la labor femenina. En particular, la Junta Central Femenina pro Ayuda a la Infancia Española y el Comité Argentino De Mujeres Pro Huérfanos Españoles organizaron desde charlas sobre el rol de las mujeres, muestras de muñecas, hasta recolección de ropa y viveres, entre

\section{anuario.}


otras. Esta actividad se reorientó en la ayuda con los refugiados y los niños de la guerra.

En un momento en que su condición de ciudadanas no estaba plenamente reconocida, este proceso cobra una dimensión mayor cuando la escala se reduce, ya que "estas agrupaciones habilitan espacios de actuación pública que las vuelve más visibles en terrenos en los que tradicionalmente no lo son tanto" (Ardanaz, 2013: 3).

Para Casas (2016), allí hubo una entrada en el ámbito de lo público que se produjo en tanto mujeres-madres. Según el autor, este rol se reforzó con los conflictos bélicos que permitieron confirmar la fuerte participación de las mujeres (junto a sus familias) en el proceso de ayuda con los republicanos. La estructura social permitió que

"Esa nueva mujer vinculada al mundo del trabajo y particularmente a la fábrica se relaciona estrechamente a las luchas de su tiempo, una mujer que se compromete con la actividad social y politica, no podia quedar ausente de la participación a favor de la causa republicana" (Casas, 2016: 199).

Si bien coincidimos con las hipótesis y el análisis de Casas (2016) en relación a las mujeres y su vinculación política en estos años, será conveniente pensar dicha participación en una continuidad con sus luchas por conquistar derechos.

En su trabajo sobre las mujeres y la Guerra Civil Española en Argentina, el autor analiza pormenorizadamente el contexto nacional en donde se desarrollan estos movimientos antifascistas, determinando que las divergencias politicas encontraron nuevas formas de canalizarse en el espacio público usando un "nuevo lenguaje politico" que persistiría en otras coyunturas similares. De acuerdo con Ardanaz (2013), en su búsqueda regional de un antifascismo caracterizado por el predominio de la militancia feminista, ubica a estas mujeres en un contexto más general que va de 1912 a 1938, "caracterizado por diversas propuestas para lograr una redefinición de la ciudadanía política en el ámbito legislativo" (Ardanaz, 2013: 8). Aunque sostiene que esta creciente acción pública femenina no es acompañada por normas que le permitan conquistar derechos.

La participación de las mujeres permaneció vinculada a prácticas que, aún en su intervención social, las ubicaban en determinadas tareas que, culturalmente y con anterioridad, se consideraban actividades 'femeninas', por ejemplo, el cuidado de niños, las tareas destinadas a roles domésticos, en muestras de muñecas, talleres textiles $\mathrm{y}$, fundamentalmente, casi siempre bajo una voluntad no violenta. Lo que no quita que las mujeres hubieran

\section{anuario.}




\section{En la retaguardia con aire de copla. La Junta Central Pro Socorro y}

Reconstrucción de España en el sur de Santa Fe 1936-1939

participado del conflicto bélico como brigadistas, evidenciando posturas más radicalizadas.

A nuestro entender, destinado a analizar el caso de la Junta, el marco del protagonismo de las mujeres reproduce los quehaceres estereotipados supuestamente femeninos como el de los cuidados, la educación y la pacificación en el contexto hostil de la entreguerra.

Poniendo el foco a nivel de lo que ocurre en el plano nacional, Dora Barrancos (2019) sostiene que a inicios de la década del '40 hubo una especial agitación en ese sentido a cargo de la Junta de la Victoria, que supo congregar tanto a las socialistas, radicales, comunistas y liberales como a un conjunto de mujeres independientes con el objetivo de frenar la expansión nazi-fascista, fenómeno que en un momento previo ya se había revelado a través de la especial solidaridad con las víctimas de la Guerra Civil Española. Hecho que, siguiendo la propuesta de Ardanaz (2013), desde una perspectiva de género en escalas más pequeñas, se complejiza la categoría misma de antifascismo como herramienta de análisis para problematizar la comprensión de este fenómeno.

\section{Notas finales}

En este trabajo intentamos recuperar la experiencia regional y local de la Junta Central Pro Socorro y Reconstrucción de España pensada como una de las entidades de ayuda al bando republicano, en el marco de la Guerra Civil Española, de mayor anclaje territorial. La misma fue una iniciativa que convocó a cientos de personas de diferentes identidades políticas, dejando entrever una forma de construcción política novedosa dentro de un ambiente caracterizado por el autoritarismo de los gobiernos conservadores en la provincia de Santa Fe.

En ese sentido, el análisis demandó un trabajo de exploración bibliográfica y de fuentes documentales que aportaran a la reflexión historiográfica sobre el objeto. La perspectiva de la historia regional nos posibilitó los mecanismos para observar un conjunto de problemáticas específicas que enriquecieron, a nuestro juicio, el concepto de antifascismo en su interpretación dinámica.

Además de convocar al campo político de las izquierdas y el liberalismo, esta Junta fue el eje a partir del cual se sumaron personas por fuera de una identidad política preestablecida. Ello puede verse en el despliegue de sus actividades. Lo que destacamos es el ensayo creativo de establecer con claridad los criterios para organizar la amplia avalancha de la solidaridad con la República española. Ensayo en tanto pudieron participar personalidades de la política, del campo intelectual, sindicatos, personalidades vinculadas a los

\section{anuario.}


centros regionales españoles, a la vez que, en la marcha pudieron dar expresión a una gran participación de las mujeres en la ayuda con las víctimas.

Lo hasta aquí estudiado nos permite decir que, a su manera, el accionar de la Junta le aportó contenido al movimiento antifascista local y anticipó las movilizaciones callejeras y el activismo social de los años `40 en Argentina.

Por último, destacamos que estas actividades, lejos de configurarse como simples actos de ayuda, tuvieron un desenvolvimiento que las transfiguró en elementos claves para interpretar las formas de hacer politica en ese contexto y en ese periodo. Elementos que dieron la pauta de novedosas expresiones que, ante el marco hostil de los sectores conservadores, devinieron en una cultura contestataria como forma de abordar la escena politica. Es decir, se trata de una cultura politica que encontraba en su andar los mecanismos para hacer frente al autoritarismo. Fue también una forma de hacer visible el pensamiento de aquello que aquejaba al mundo, de alli la importancia de disputar el espacio público como el escenario en donde las imágenes y los discursos -en tanto lenguajes que construyen sentido social- se pusieron en juego. Y se constituyeron en el punto de intersección entre el drama local y las perplejidades de la guerra civil europea.

\section{Bibliografia}

Ardanaz, E. (2013). "Pelando papas se combate al fascismo": roles y funciones en las asociaciones antifascistas de Bahía Blanca durante la Guerra Civil Española. Cuadernos de $H$ Ideas (7). Recuperado de http://perio.unlp.edu.ar/ojs/index.php/cps/index

Armida, M. y Fernández, S. (2000). Una ciudad en transición y crisis (1930 1943). En Plá, A. (coord.), Rosario en la Historia (de 1930 a nuestros dias). Rosario: UNR Editora.

Bandieri, S. (2018). La perspectiva regional y local. Un camino posible para una historia argentina renovada. Quinto Sol (22), pp. 1-51. Recuperado de http://dx.doi.org/10.19137/qs.v22i3.3337

Barrancos, D. (2019). Devenir Feminista. Una trayectoria politico/intelectual. Antología esencial. Buenos Aires: Editorial de la Facultad de Filosofia y Letras, Universidad Nacional de Buenos Aires. Disponible en 
http://biblioteca.clacso.edu.ar/clacso/se/20191004095214/Dora_Barrancos. pdf

Baumann, G. (2009). Los Voluntarios Latinoamericanos en la Guerra Civil Española. La Mancha: Ediciones de la Universidad de Castilla.

Bisso, A. (2005). Acción Argentina. Un antifascismo nacional en tiempos de guerra mundial. Buenos Aires: Prometeo.

Bisso, A. (2007). El Antifascismo argentino. Selección documental y estudio preliminar. Buenos Aires: Cedindi editores.

Bocanegra, L. (2014). El Fin de la Guerra Civil española y el exilio republicano: visiones y prácticas de la sociedad argentina a través de la prensa. El caso de Mar del Plata, 1939. (Tesis de doctorado). Lérida: Universitat de Lleida.

Bohoslavsky, E. (2018). Debates y conflictos de la historia regional en la Argentina actual. Quinto Sol, (22), pp. 1-51. Recuperado de http://dx.doi.org/10.19137/qs.v22i3.3337

Boragina, J., Dorado, G., González, L. y Sommaro, E. (2008). Voluntarios de Argentina en la Guerra Civil Española, Buenos Aires: Centro Cultural de la Cooperación Floreal Gorini.

Camaño Semprini, R. (2014). Ecos de la Guerra Civil Española. La derecha nacionalista y los frentes antifascistas en los espacios locales argentinos. Diacronie. Studi di storia contemporanea, (17) 1.

Campione, D. (2018). La guerra civil española. Argentina y los argentinos. Buenos Aires: Ediciones Luxemburgo.

Carr, R. (1974). Estudios sobre la República y la Guerra Civil española. España: Ariel.

Casas, S. (2016). La guerra civil española y su recepción en la Argentina: las mujeres y su participación en los comités de ayuda al sector republicano. Cuadernos de Marte, 11, pp. 175-201.

Cattaruza, A. (2006). La traducción y sus límites. La guerra civil española. Buenos Aires: Editorial Biblos.

Cingolani, A. y Frutos, R. (2003). El Partido Comunista y el movimiento obrero en los '30. (Seminario Regional). Facultad de Humanidades y Artes, Universidad Nacional de Rosario. 
Cucurullo, S. y Sdrigiotti, C. (1999). El impacto de la Guerra Civil Española en la Colectividad española de Rosario: el caso del Centro Navarro. (Seminario Regional) Facultad de Humanidades y Artes, Universidad Nacional de Rosario.

De Privitellio, L. (2002). La politica bajo el signo de la crisis. En Cataruzza, A. (comp.) Crisis económica, avance del estado e incertidumbre política (19301943). Buenos Aires: Sudamericana.

Devoto, F. (2001). El revés de la trama: politicas migratorias y prácticas administrativas en la Argentina (1919-1949). Desarrollo Económico, (41) 162, pp. 281-304.

Edelman, F. (1996). Banderas, Pasiones, Camaradas. Buenos Aires: Dirple.

Edelman, F. (2013). Rebeldía militante. Extractos autobiográficos de una brigadista republicana. Buenos Aires: Ospaaal.

Etchebéhère, M. (2014). Mi guerra de España. Buenos Aires: Eudeba.

Fernández, S. (2017). Sociabilidades en pugna. El impacto de la guerra civil española en perspectiva asociativa. Rosario, Argentina. Historia (São Paulo), (36) 114, pp. 1-22. Recuperado de https://www.scielo.br/pdf/his/v36/01019074-his-36-e114.pdf

Fernández, S. (2007). Los estudios de la historia regional y local de la base territorial a la perspectiva teórico-metodológica. En Fernández, S. (comp.) Más allá del territorio. La historia regional y local como problema. Discusiones, balances y proyecciones. Rosario: Prohistoria.

Figallo, B. (2016). Con la república y contra la república. La Argentina y la guerra civil española. En Temas de Historia Argentina y de América (24).

Halperín Donghi, T. (2013). La argentina y la tormenta del mundo. Ideas e ideologias entre 1930 y 1945. Buenos Aires: Siglo XXI.

Hernández, A. (2015). Con la Marca en el Orillo. La memoria de los héroes que no tienen monumento. Rosario: Ediciones de autor.

Hobsbawm, E. (2003). Historia del siglo XX. Buenos Aires: Crítica.

López Cantera, M. (2017). El anticomunismo argentino entre 1930 y 1943: los origenes de la construcción de un enemigo. The International Newsletter of Communist Studies, 29-30; pp. 71-80. Recuperado de https://incs.ub.rub.de/index.php/INCS/article/view/702/660 
Martín, M. (2019). Derecha católica argentina y organización laical. La Primera Semana de Estudios Sociales de Rosario acerca del Comunismo. VI Jornadas Internacionales de Problemas Latinoamericanos. Universidad de Valparaíso, Chile.

Martín, M. (1993). Sindicalismo católico y Estado corporativo. Cuadernos deCiesal, (1) 1.

Mauro, D. (2013). Reformismo liberal y politica de masas. Demócratas progresistas y radicales en Santa Fe (1921 - 1937). Rosario: Prohistoria.

McGee Deutsch, S. (2013). Mujeres, antifascismo y democracia: la junta de la victoria, 1941-1947. Anuario IEHS 28, pp. 157 -175.

McGee Deutsch, S. (2012). Argentine women against fascism: the Junta de la Victoria, 1941-1947. Politics, Religion \& Ideology, (13), 2, pp. 221-236.

Montenegro, S. (2002). La Guerra Civil Española y la Política Argentina. (Tesis de doctorado). Universidad Complutense de Madrid, Madrid.

Moradiellos, E. (2012). La guerra de España (1936-1939). Estudios y controversias. Barcelona: RBA.

Núñez Seixas, X. (2013). Notas sobre los españoles en Rosario (1934): una vindicación republicana de la inmigración española en la Argentina. Revista de Indias, (73) 259, pp. 857-874.

Pasolini, R. (2016). Los marxistas liberales. Antifascismo y cultura comunista en el siglo XX. Buenos Aires: Editorial Sudamericana.

Pasquali, L. (2016). Mujeres y politica en escenarios de conflicto del siglo XX. Rosario: Ediciones ISHIR.

Piazzesi, S. (2009). Conservadores en provincia. El iriondismo santafesino, 1937-1943. Santa Fe: Universidad Nacional del Litoral.

Quijada, M. (1991). Aires de República, aires de cruzada: la Guerra Civil española en Argentina. Barcelona: Sendai ediciones.

Romero, L. (2011). La Guerra Civil Española y la polarización ideológica y política: la Argentina 1936-1946. Anuario Colombiano de Historia Social y de la Cultura, (38) 2, pp. 17-37.

Schwarzstein, D. (2000). Entre Franco y Perón. Memoria e Identidad del Exilio Republicano Español en Argentina. Barcelona: Crítica. 
Scott, J. (1983). Women in History. The Modern Period. Past \& Present, 101, pp. $141-157$.

Suárez, P. (2002). Buscando al Fascismo. Los comunistas rosarinos y el fascismo, 1928 - 1935. (Seminario Regional). Facultad de Humanidades y Artes, Universidad Nacional de Rosario.

Traverso, E. (2009). A sangre y fuego: de la guerra civil europea 1914-1945. Buenos Aires: Prometeo Libros.

Videla, O. (2006). Desarrollo agroexportador y conflictividad social, 19121930. En Videla, O. et al. El Siglo Veinte. Problemas sociales, politicos de Estado y economías regionales (1912-1976). Rosario: Prohistoria Ediciones y Diario La Capital.

Vilar, P. (2000). La guerra Civil Española. Barcelona: Critica.

Yunque, Á. (2006). España, 1936. Buenos Aires: Ediciones BP.

\section{Prensa}

E1 Orden, Santa Fe, 1937.

La Capital, Rosario, 1936; 1937; 1938; 1939.

La Tribuna, Rosario 1936; 1937; 1938; 1939.

La Vanguardia, Buenos Aires. 1936.

Nueva España, Rosario, 1939.

\section{Otros documentos}

Colección Isaac Calzadilla. Museo Histórico Provincial Julio A. Marc. Rosario. Santa Fe. 